\title{
Impact of Dose and Route of administration on Antibody Responses of Chickens Inoculated with inactivated Avian Influenza H5 Vaccine.
}

\author{
Abubakar Ojone Woziri ( $\nabla$ woziriabubakar@gmail.com ) \\ Ahmadu Bello University Faculty of Veterinary Medicine https://orcid.org/0000-0001-6465-7704 \\ Clement Adebajo Meseko \\ NVRI: National Veterinary Research Institute \\ Faridah Ibrahim Nasir \\ Ahmadu Bello University Faculty of Veterinary Medicine \\ Khadijat Abdulkarim \\ Ahmadu Bello University Faculty of Science \\ Folorunso Oludayo Fasina \\ FAO: Food and Agriculture Organization of the United Nations \\ Jibril Adamu \\ Ahmadu Bello University Faculty of Veterinary Medicine \\ Paul Ayuba Abdu \\ Ahmadu Bello University Faculty of Veterinary Medicine
}

\section{Original Article}

Keywords: Avian Influenza, Inactivated H5 Vaccine, Dose, Intramuscular, Subcuteneous, Chickens, Nigeria

Posted Date: February 1st, 2021

DOI: https://doi.org/10.21203/rs.3.rs-158047/v1

License: () (i) This work is licensed under a Creative Commons Attribution 4.0 International License. Read Full License 


\section{Abstract}

Avian influenza viruses (AIV) poses significant threats to human and animal lives globally, and in spite of availability of vaccines, only few studies have established the role of passively acquired antibodies in the protection of chickens in sub Saharan Africa. The present study evaluated the influence of dose and route of administration of Al H5 inactivated vaccine on the humoral immune response of ISA brown chickens. Ninety "one-day-old" chickens were purchased from three major commercial hatcheries A, B and C ( $n=30$ chicks per hatchery), respectively. Results showed significant differences $(P<0.001)$ in the mean antibody titre levels at day 21 of age between chicks from hatcheries $C(2,205.0 \pm 409.1)$ and $A(57.7 \pm 49.9)$ at 21 days of age when either $0.2 \mathrm{ml}$ or $0.5 \mathrm{ml}$ of the vaccine was administered IM or SC. In addition, there were intra- and inter dose significant differences $(P<0.001)$ between the chicks at $21,28,35$ and 42 days of age. Furthermore, intra- and inter route significant differences $(P<0.001)$ were detected between the chicks at 21 and 35 days of age. Overall, the Al H5 vaccine studied had variable outcomes and poorly immunogenic. Further studies should be conducted to characterize the T-and B-lymphocytes in chickens post Al H5 vaccines administration, and evaluate the sequence homologies between imported Al H5 vaccines and circulating AIV strains in Nigeria.

\section{Introduction}

Avian influenza virus (AIV), a single-stranded, negative-sense RNA virus, is a member of the family Orthomyxoviridae, genus Orthomyxovirus, and diseases caused by type A influenza viruses (IAVs) are common among members of the order Anseriformes (ducks, geese and swans) (Swayne, 2008; Brown, 2010; Germundsson et al., 2010; Marchenko et al., 2012; Tonnessen et al., 2013; Swayne, 2015). However, many influenza A virus subtypes in wild birds may differ between species and geographical locations, with great tendencies for evolution over time (Germundsson et al., 2010; Kang et al., 2010; Wille et al., 2014).

AIV has gained global recognition as one of the major diseases of public health and economic importance. Al vaccines are often used in integrated control strategies to protect poultry against HPAI such as H5N1, as vaccination decrease disease prevalence and reduce viral shedding among infected poultry (Swayne and Kapczynski, 2008). Likewise, vaccination against HPAl has shown decreased rates of environmental contamination, especially where enforcement of biosecurity is impracticable (Swayne and Kapczynski, 2008). However, in spite of the fact that mucosal routes serve as portals of entry for AIVs into susceptible hosts, many of the Al vaccines approved for use in poultry are inactivated whole virus vaccines, delivered with water-in-oil emulsions (Swayne and Kapczynski, 2009) through parenteral routes, and requiring adjuvants for the induction of antigen-specific immune responses (Singh et al., 2015).

Currently, there are three types of AIV vaccines that have been licensed or approved for use in poultry (van den Berg et al., 2008); and between 2002 and 2010, over 113 billion doses of Al vaccines have been used in poultry as oil-emulsified inactivated whole Al vaccines (95.5\%) and live vectored vaccines (4.5\%) [13]. Most commercial vaccines rely on the generation of neutralizing antibodies against the antigenic protein - haemagglutinin (HA). However, the inability of neutralizing antibodies to cross-react with heterotypic viruses or even variant viruses of the same HA subtype limits the efficacy of such Al vaccines in providing the required protection against field infection (Sautto et al., 2018; Jang and Seong, 2019).

Like in many developing countries, poultry production in Nigeria is an important income generating activity, contributing to the general economy through its linkage with other sectors (Oladokun et al., 2012). However, in spite of the number of outbreaks of HPAl caused by H5N1 and H5N8 in the presence of various surveillance efforts in Nigeria, vaccination policies against AIVs have not gained government approval; hence, farm owners decide which vaccine to use, if any, in a bid to protect their investments. However, a study has shown that some of these Al vaccines, when used, could confer partial protection in targeted host species and thus lead to vaccine-induced escape mutants, which may either revert to virulence or adapt to new hosts (Abdallah and Hassanin, 2015). Previous reports have also indicated that improper antigenic matching between vaccines and circulating viruses might reduce vaccine efficacy (Chen, 2009; Kapczynski et al., 2013). Studies in humans have shown that H5N1 viruses elicit a poor humoral immune response, providing low antibody titres that fade over a short period (Nolan et al., 2008; Juno et al., 2012). As most Al vaccines used for poultry globally are inactivated, current knowledge of immunity against Al 
is largely based on humoral immune responses (Kapczynski et al., 2011). The present study was therefore aimed at evaluating the influence of dose and route of administration of Al H5 inactivated vaccine on the humoral immune response of ISA brown chickens. This is expected to provide baseline data on humoral immune response of vaccinated birds in Nigeria.

\section{Materials And Methods}

\subsubsection{Experimental Chickens}

A total of 90 one-day-old ISA Brown chickens were purchased from three major commercial hatcheries A, B and C ( $n=30$ chicks per hatchery), respectively. The birds were housed in a hygienic environment at the Poultry Research facility of the Faculty of Veterinary Medicine, Ahmadu Bello University, Nigeria. All the chicks were wing-banded with alpha-numeric tags for ease of identification.

\subsubsection{Vaccine}

An inactivated oil-emulsion avian influenza $\mathrm{H} 5$ vaccine (AVIFLU ${ }^{\circledR} \mathrm{H} 5$ - Izovac, Italy, containing H5N9 subtype antigen recommended for use in chickens at a dose of either 0.25 or $0.5 \mathrm{ml}$ subcutaneously or intramuscularly) was used.

\subsubsection{Enzyme-Linked Immunosorbent Assay Kit}

A 96-well enzyme-linked immunosorbent assay (ELISA) kit (ProFLOK ${ }^{\circledR}$, Zoetis Inc., U.S.A) was used for the in vitro assessment of avian influenza $\mathrm{H} 5$ antibodies in the sera of chickens according to the manufacturer's instructions.

\subsection{Methods:}

\subsubsection{Experimental Design}

\subsubsection{Treatment groups}

The chicks were divided on the day of arrival into three (3) groups of A, B and C ( $n=30$ per hatchery), respectively. All the chicks were wing-banded with alphanumeric ribbons for ease of identification, and housed in clean and hygienic elevated wire cages (10 chicks per $60 \mathrm{~cm}$ x $55 \mathrm{~cm}$ cell) in the Poultry Research Unit of the Veterinary Teaching Hospital, Ahmadu Bello University, Zaria - Nigeria. The chicks were acclimatized for 14 days prior to the commencement of the experiment. All chicks were granted access to water and commercial broiler's starter feed ad libitum throughout the duration of the experiment.

\subsubsection{Treatment Protocols}

The chicks from hatchery A were subdivided into three subgroups of A1, A2 and A3 ( $n=10$ each) based on the dose of the Al H5 vaccine to be administered. Chicks in $\mathrm{A} 1$ were administered $0.2 \mathrm{ml}$ of the vaccine via either the subcutaneous (at the nape of the neck) $(n=5)$ or intramuscular routes (in the breast muscles) $(n=5)$, respectively at days 14 and 28 of age. Chicks in A2 were administered $0.5 \mathrm{ml}$ of the vaccine via either the subcutaneous $(n=5)$ or intramuscular routes $(n=5)$, respectively at days 14 and 28 of age. Chicks in A3 were administered $0.7 \mathrm{ml}$ of the vaccine via either the subcutaneous $(n=5)$ or intramuscular routes $(n=5)$, respectively on days 14 and 28 of age.

Chicks from hatcheries $B$ and $C$ were treated as those from hatchery $A$.

All the chicks were monitored daily for welfare, apparent clinical signs of infection and or adverse vaccine reaction.

\subsubsection{Collection of Blood Samples}

\subsubsection{Evaluation of the Humoral Immune Responses of Pullet Chicks to commercial Inactivated Al H5 vaccine}

Two (2) $\mathrm{ml}$ of blood was collected via the brachial vein of 3 randomly selected chicks in each subgroup $(n=3)$ using sterile 23G hypodermic needles and syringes at day 14 of age into plain vacutainers for serology. The tubes were kept standing at room temperature for $24 \mathrm{~h}$ for serum formation. Thereafter, serum from each tube was aspirated using sterile pipettes into another set 
of $1 \mathrm{ml}$ labelled microcentrifuge tubes (Eppendorf ${ }^{\circledR}$ ), and stored at $-20{ }^{\circ} \mathrm{C}$ until assayed for serum ant-AIV antibodies. Blood sampling procedure was repeated at $21,28,35$, and 42 days of age.

\subsubsection{Analyses of samples}

\subsubsection{Assessment of Antibody Response to Avian Influenza H5 inactivated vaccine}

Sandwich ELISA kit (ProFlok ${ }^{\circledR}$ ) was used to assess the anti-Al antibodies in sera post-vaccination with the AIV H5 inactivated vaccine. Briefly, all the reagents and samples were removed from the freezer and allowed to thaw at room temperature for 30 min before the start of the assay. The samples were thawed and thoroughly mixed on a shaker prior to dilution. The sera samples were then diluted 50-fold (1:50) in sample dilution microplates and the diluted samples were allowed to equilibrate for $5 \mathrm{~min}$ before they were transferred to ELISA microplates. The positive control, negative control and sample wells were set as appropriate. $50 \mu \mathrm{l}$ of the dilution buffer was added to each well. $50 \mu \mathrm{l}$ each of the positive and negative controls were then added to the positive control wells ( $\mathrm{A} 1, \mathrm{~A} 3$ and $\mathrm{H} 11)$ and negative control wells (A2, $\mathrm{H} 10$ and $\mathrm{H} 12) .50 \mu$ of each sample dilution from the microplate was also transferred to the respective pre-labelled matching wells. The plates were then covered with an adhesive strip and incubated at $25^{\circ} \mathrm{C}$ for $30 \mathrm{~min}$ in a dark chamber. The content of each well in the test microplates were discarded by sharply inverting and tapping the bottom of the plates. $300 \mu \mathrm{l}$ of the wash solution was added to each test well and allowed to soak for $3 \mathrm{~min}$. The contents were again discarded by inverting and tapping the bottom of the plates. Washing was repeated two more times. $100 \mu \mathrm{l}$ of the conjugate solution was then added to each test well and the plates incubated for 30 min at room temperature. The plates were then washed again as earlier described before adding $100 \mu$ of the substrate solution to each test well. The plates were incubated again at room temperature for $15 \mathrm{~min} .100 \mu \mathrm{l}$ of the stop solution was then added to each test well to stop further reactions. The optical density (O.D) of each well on the plates were read at $450 \mathrm{~nm}$ wavelength with an ELISA reader (UNIEQUIP ${ }^{\circledR}$ ) within 5 min of adding the stop solution.

\subsubsection{Data Analyses}

All the OD values obtained from this study were inputted in computer ( $\mathrm{Hp}{ }^{\circledR}$ Pavilion dv6) and analyzed using GraphPad Prism statistical software version 5.3 (Graph Pad software, San Diego, California, USA). Data obtained were expressed as mean \pm standard error of means (SEM) and a two-way analysis of variance (ANOVA) followed by a post-hoc test (Bonferroni posttest) was used to determine significant differences between variables among all the sampled chicks, and $P$-values less than 0.05 was considered statistically significant at $95 \%$ confidence interval $(\mathrm{Cl})$. All data were presented in tables using Microsoft ${ }^{\circledR}$ excel version 13.

\section{Results}

\subsection{Effects of Different Doses of Avian Influenza H5 Killed Vaccine Administered via the}

\section{Intramuscular Route on the Humoral Immune Responses of Chickens from Different Commercial Hatcheries}

There were no statistically significant differences in the mean antibody titres in the chicks from hatcheries $A, B$ and $C$ administered $0.2 \mathrm{ml}, 0.5 \mathrm{ml}$ and $0.7 \mathrm{ml}$ of the inactivated Avian influenza $\mathrm{H} 5$ vaccine at 14 and 35 days of age $(P>0.05)($ Table 1). However, there was a highly significant difference in the mean antibody titre levels between the chicks from hatcheries $C$ $(2,205.0 \pm 409.1)$ and $\mathrm{A}(57.7 \pm 49.9)$ at 21 days of age when the chicks were administered $0.2 \mathrm{ml}$ of the inactivated $\mathrm{H} 5 \mathrm{Al}$ vaccine $(P<0.001)($ Table 1$)$.

At 21 days of age, there was a significant difference $(P<0.001)$ between the mean antibody titres of $C(2,205.0 \pm 409.1)$ administered $0.2 \mathrm{ml}$ of the vaccine and $\mathrm{A}(776.7 \pm 420.0)$ administered $0.5 \mathrm{ml}$ of the vaccine, as well as between $\mathrm{C}(1,834.3 \pm$ 
638.9) administered $0.7 \mathrm{ml}$ of the $\mathrm{H} 5$ vaccine and chicks from $\mathrm{A}(57.7 \pm 49.9)$ administered $0.2 \mathrm{ml}$ of the vaccine $(P<0.001)$. There was also statistical significant differences $(P<0.001)$ in mean antibody titres of the chicks at 21 days of age from $C$ $(2,205.0 \pm 409.1)$ administered $0.2 \mathrm{ml}$ of the vaccine and chicks from $\mathrm{B}(260.7 \pm 124.8)$ administered $0.2 \mathrm{ml}$ of the vaccine, as well as between $C(1,993.0 \pm 978.4)$ administered $0.5 \mathrm{ml}$ of the vaccine and chicks from $B(260.7 \pm 124.8)$ administered $0.2 \mathrm{ml}$ of the vaccine $(P<0.001)$ (Table 4.3). There were also high significant differences $(P<0.001)$ in the mean antibody titres at 21 days of age between chickens from hatcheries $C 3(1,834.3 \pm 638.9)$ and $B 1(260.7 \pm 124.8), C 1(2,205.0 \pm 409.1)$ and B2 (399.0 \pm 160.1) $(P<0.001), C 1(2,205.0 \pm 409.1)$ and $A 3(212.3 \pm 209.8)(P<0.001), C 1(2,205.0 \pm 409.1)$ and $B 3(221.7 \pm 51.6)(P<$ 0.001), C2 (1993.0 \pm 978.4$)$ and A2 (776.7 \pm 420.0$)(P<0.05), B 2(399.0 \pm 160.1)$ and C2 (1993.0 \pm 978.4$)(P<0.01), C 3(1834.3$ \pm 638.9) and B2 (399.0 \pm 160.1) $(P<0.01), C 2(1993.0 \pm 978.4)$ and $A 3(212.3 \pm 209.8)(P<0.001), C 2(1993.0 \pm 978.4)$ and B3 $(221.7 \pm 51.6)(P<0.001), C 3$ and $A 3(P<0.01)$ and between $C 3(1834.3 \pm 638.9)$ and $B 3(221.7 \pm 51.6)(P<0.01)$ that were vaccinated IM (Table 1). The results further showed that at 28 days of age, there were significant differences $(P<0.01)$ between the mean antibody titres between the chicks from $\mathrm{C} 1(1,372.3 \pm 341.1)$ and $\mathrm{B} 1(0.0 \pm 0.0), \mathrm{C} 1(1,372.3 \pm 341.1)$ and $\mathrm{A} 2(59.0 \pm$ 59.0) $(P<0.05), C 1(1,372.3 \pm 341.1)$ and $B 2(84.0 \pm 51.3)(P<0.05), C 1(1,372.3 \pm 341.1)$ and $A 3(47.0 \pm 44.0)(P<0.05)$ and between $\mathrm{C} 1(1,372.3 \pm 341.1)$ and $\mathrm{B} 3(0.0 \pm 0.0)(P<0.01)$ vaccinated IM (Table 1).

At 42 days of age, the findings from this study indicated significant differences in the mean antibody titres of the vaccine between the chickens from $C 2(1,822.3 \pm 176.7)$ and $A 1(288.3 \pm 257.1)(P<0.01), B 1(4.0 \pm 4.0)$ and A2 $(1,327.3 \pm 199.3)(P<$ 0.05), $C 2(1,822.3 \pm 176.7)$ and $B 1(4.0 \pm 4.0)(P<0.001), A 2(1,327.3 \pm 199.3)$ and $A 3(66.7 \pm 20.4)(P<0.05), A 2(1,327.3 \pm$ 199.3) and $B 3(2.7 \pm 2.7)(P<0.05), C 2(1,822.3 \pm 176.7)$ and $A 3(66.7 \pm 20.4)(P<0.001), C 2(1,822.3 \pm 176.7)$ and $B 3(2.7 \pm$ 2.7) $(P<0.001)$, as well as between $C 2(1,822.3 \pm 176.7)$ and $C 3(687.0 \pm 393.5)(P<0.05)$ vaccinated IM $($ Table 1$)$.

\subsection{Effects of different doses of avian influenza H5 killed vaccine administered via the subcutaneous route on the humoral immune responses of chicks from different commercial hatcheries in Nigeria}

There were no statistically significant differences $(P>0.05)$ in the mean antibody titres in the chicks from hatcheries $A, B$ and $C$ administered $0.2 \mathrm{ml}, 0.5 \mathrm{ml}$ and $0.7 \mathrm{ml}$ of the $\mathrm{H} 5$ vaccine at days 14 and 42 of age (Table 2). However, at 21 days of age, the findings showed a highly significant difference $(P<0.001)$ in the mean antibody titres between the chicks from hatcheries $C$ $(2,444.3 \pm 1,110.6)$ and $A(53.3 \pm 36.0)$ that were administered $0.2 \mathrm{ml}$ of the vaccine via the subcutaneous route (Table 2$)$. Also, at 21 days of age, there was significant difference between the mean antibody titres of chicks from $C(2,444.3 \pm 1,110.6)$ administered $0.2 \mathrm{ml}$ of the vaccine and chicks from $B(646.3 \pm 237.9)$ administered $0.2 \mathrm{ml}$ of the vaccine $S C(P<0.01)$, as well as between $C(2,444.3 \pm 1,110.6)$ administered $0.2 \mathrm{ml}$ of the vaccine and chicks from $\mathrm{A}(469.3 \pm 444.1)$ administered $0.5 \mathrm{ml}$ of the vaccine SC $(P<0.01)$ (Table 2$)$

Table 1. Effects of different doses of avian influenza H5 inactivated vaccine administered at 14 and 28 days of Age via intramuscular route on the

antibody responses of ISA brown chicks from three different commercial hatcheries in Nigeria 


\begin{tabular}{|c|c|c|c|c|c|c|c|c|c|}
\hline & \multicolumn{9}{|c|}{ Dose of Vaccine } \\
\hline & \multicolumn{4}{|c|}{$0.2 \mathrm{ml}$} & \multicolumn{3}{|l|}{$0.5 \mathrm{ml}$} & \multicolumn{2}{|l|}{$0.7 \mathrm{ml}$} \\
\hline & $\mathrm{A} 1$ & B1 & $\mathrm{C} 1$ & A2 & B2 & $\mathrm{C} 2$ & A3 & B3 & $\mathrm{C} 3$ \\
\hline $\begin{array}{l}\text { Age } \\
\text { (days) }\end{array}$ & \multicolumn{3}{|c|}{ Antibody titre (mean \pm SEM) } & \multicolumn{3}{|c|}{ Antibody titre (mean \pm SEM) } & \multicolumn{3}{|c|}{ Antibody titre (mean \pm SEM) } \\
\hline 14 & $\begin{array}{l}293.7 \pm \\
53.9^{a}\end{array}$ & $\begin{array}{l}182.7 \\
\pm \\
129.1^{\mathrm{a}}\end{array}$ & $\begin{array}{l}354.0 \pm \\
354.0^{a}\end{array}$ & $\begin{array}{l}27.3^{ \pm} \\
21.6^{\mathrm{a}}\end{array}$ & $\begin{array}{l}69.3 \pm \\
16.6^{\mathrm{a}}\end{array}$ & $\begin{array}{l}82.0^{ \pm} \\
43.1^{\mathrm{a}}\end{array}$ & $\begin{array}{l}89.0 \pm \\
65.2^{\mathrm{a}}\end{array}$ & $\begin{array}{l}88.7 \pm \\
88.7^{a}\end{array}$ & $\begin{array}{l}203.0 \pm \\
191.1^{a}\end{array}$ \\
\hline 21 & $\begin{array}{l}57.7 \pm \\
49.9^{\mathrm{a}}\end{array}$ & $\begin{array}{l}260.7 \\
\pm \\
124.8^{b}\end{array}$ & 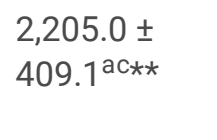 & $\begin{array}{l}776.7 \pm \\
420.0^{c d * \star}\end{array}$ & $\begin{array}{l}399.0 \pm \\
160.1^{\text {bce }}\end{array}$ & $\begin{array}{l}1,993.0 \pm \\
978.4^{\text {abdef }}\end{array}$ & $\begin{array}{l}2,12.3 \pm \\
209.8^{\mathrm{cfg} \star \star}\end{array}$ & $\begin{array}{l}221.7 \pm \\
51.6^{\text {beh } \star \star}\end{array}$ & $\begin{array}{l}1,834.3 \pm \\
638.9^{\text {abeghi** }}\end{array}$ \\
\hline 28 & $\begin{array}{l}424.7 \pm \\
321.4^{\text {ab }}\end{array}$ & $\begin{array}{l}0.0 \pm \\
0.0^{\mathrm{b}}\end{array}$ & $\begin{array}{l}1,372.3 \pm \\
341.1^{\text {cdegh }_{\star \star}}\end{array}$ & $\begin{array}{l}59.0 \pm \\
59.0^{d}\end{array}$ & $\begin{array}{l}84.0 \pm \\
51.3^{\mathrm{e}}\end{array}$ & $\begin{array}{l}576.7 \pm \\
500.7^{f}\end{array}$ & $\begin{array}{l}47.0 \pm \\
44.0^{9}\end{array}$ & $\begin{array}{l}0.0 \pm \\
0.0^{\mathrm{h}}\end{array}$ & $\begin{array}{l}703.0^{ \pm} \\
352.0^{\mathrm{i}}\end{array}$ \\
\hline 35 & $\begin{array}{l}968.7 \pm \\
268.2^{a}\end{array}$ & $\begin{array}{l}678.3 \\
\pm \\
376.8^{a}\end{array}$ & $\begin{array}{l}208.3 \pm \\
101.7^{a}\end{array}$ & $\begin{array}{l}1,080.7 \pm \\
224.2^{a}\end{array}$ & $\begin{array}{l}642.0 \pm \\
341.1^{a}\end{array}$ & $\begin{array}{l}135.0 \pm \\
84.5^{a}\end{array}$ & $\begin{array}{l}566.3 \pm \\
351.8^{a}\end{array}$ & $\begin{array}{l}970.0 \pm \\
486.2^{\mathrm{a}}\end{array}$ & $\begin{array}{l}214.0 \pm \\
74.3^{a}\end{array}$ \\
\hline 42 & $\begin{array}{l}288.3 \pm \\
257.1^{a}\end{array}$ & $\begin{array}{l}4.0^{ \pm} \\
4.0^{\mathrm{b}}\end{array}$ & $\begin{array}{l}932.3^{ \pm} \\
550.3^{\mathrm{c}}\end{array}$ & $\begin{array}{l}1,327.3 \pm \\
199.3^{\text {bdgh }}\end{array}$ & $\begin{array}{l}775.3 \pm \\
399.8^{\mathrm{e}}\end{array}$ & $\begin{array}{l}1,822.3 \pm \\
176.7^{\mathrm{abf}}\end{array}$ & $\begin{array}{l}66.7 \pm \\
20.4^{\mathrm{g}}\end{array}$ & $\begin{array}{l}2.7 \pm \\
2.7^{\mathrm{h}}\end{array}$ & $\begin{array}{l}687.0 \pm \\
393.5^{i}\end{array}$ \\
\hline
\end{tabular}

Mean \pm SEM values in the same row with multiple superscripts are statistically significantly different at $P<0.05$ according to Bonferroni Posthoc test.

Mean \pm SEM values in the same row with same and or single superscript are NOT statistically significantly different at $P>0.05$ according to Bonferroni Posthoc test.

Key:

A, B $C=$ Chicks from the three commercial hatcheries

SEM $=$ Standard error of mean

Table 2. Effects of different doses of avian influenza H5 inactivated vaccine administered at 14 and 28 days of Age via subcutaneous route on the

antibody responses of ISA brown chickens from three different commercial hatcheries in Nigeria 


\begin{tabular}{|c|c|c|c|c|c|c|c|c|c|}
\hline & \multicolumn{9}{|c|}{ Dose of Vaccine } \\
\hline & \multicolumn{4}{|c|}{$0.2 \mathrm{ml}$} & \multicolumn{2}{|l|}{$0.5 \mathrm{ml}$} & \multicolumn{3}{|c|}{$0.7 \mathrm{ml}$} \\
\hline & $\mathrm{A} 1$ & B1 & $\mathrm{C} 1$ & A2 & B2 & $\mathrm{C} 2$ & A3 & B3 & $\mathrm{C} 3$ \\
\hline $\begin{array}{l}\text { Age } \\
\text { (days) }\end{array}$ & \multicolumn{3}{|c|}{ Antibody titre (mean \pm SEM) } & \multicolumn{3}{|c|}{ Antibody titre (mean \pm SEM) } & \multicolumn{3}{|c|}{ Antibody titre (mean \pm SEM) } \\
\hline 14 & $\begin{array}{l}293.7 \pm \\
53.9^{a}\end{array}$ & $\begin{array}{l}182.7 \pm \\
129.1^{\mathrm{a}}\end{array}$ & $\begin{array}{l}354.0 \pm \\
354.0^{\mathrm{a}}\end{array}$ & $\begin{array}{l}27.3 \pm \\
21.6^{a}\end{array}$ & $\begin{array}{l}69.3 \pm \\
16.6^{\mathrm{a}}\end{array}$ & $\begin{array}{l}82.0 \pm \\
43.1^{\mathrm{a}}\end{array}$ & $\begin{array}{l}89.0 \pm \\
65.2^{\mathrm{a}}\end{array}$ & $\begin{array}{l}88.7 \pm \\
88.7^{a}\end{array}$ & $\begin{array}{l}203.0 \pm \\
191.1^{a}\end{array}$ \\
\hline 21 & $\begin{array}{l}53.3 \pm \\
36.0^{\mathrm{ac}}\end{array}$ & $\begin{array}{l}646.3 \pm \\
237.9^{\mathrm{bc}}\end{array}$ & $\begin{array}{l}2444.3 \pm \\
1110.6^{\text {cdefghi }}\end{array}$ & $\begin{array}{l}469.3 \pm \\
444.1^{d}\end{array}$ & $\begin{array}{l}568.3 \pm \\
151.2^{\mathrm{e}}\end{array}$ & $\begin{array}{l}131.7 \pm \\
69.4^{f}\end{array}$ & $\begin{array}{l}881.0 \pm \\
215.4^{\mathrm{g}}\end{array}$ & $\begin{array}{l}293.7 \pm \\
168.4^{\mathrm{h}}\end{array}$ & $\begin{array}{l}876.0 \pm \\
539.3^{i}\end{array}$ \\
\hline 28 & $\begin{array}{l}554.3 \pm \\
487.0^{\mathrm{a}}\end{array}$ & $\begin{array}{l}61.0 \pm \\
38.4^{\mathrm{bdf}}\end{array}$ & $\begin{array}{l}371.7 \pm \\
371.7^{\mathrm{c}}\end{array}$ & $\begin{array}{l}1,639.3 \pm \\
1451.8^{\text {degh }}\end{array}$ & $\begin{array}{l}14.0 \pm \\
1.0^{\text {ef }}\end{array}$ & $\begin{array}{l}1,653.7 \pm \\
181.3^{\text {fgh }}\end{array}$ & $\begin{array}{l}182.7 \pm \\
115.7^{9}\end{array}$ & $\begin{array}{l}171.3 \pm \\
171.3^{\mathrm{h}}\end{array}$ & $\begin{array}{l}321.7 \pm \\
218.6^{i}\end{array}$ \\
\hline 35 & $\begin{array}{l}1,271.0 \pm \\
163 \cdot 7^{a}\end{array}$ & $\begin{array}{l}1,196.0 \pm \\
113.8^{b}\end{array}$ & $\begin{array}{l}46.7 \pm \\
13.5^{\mathrm{ce}}\end{array}$ & $\begin{array}{l}1,169.3 \pm \\
248.1^{d}\end{array}$ & $\begin{array}{l}1,500.0 \\
\pm 60.1^{\mathrm{ei}}\end{array}$ & $\begin{array}{l}392.0 \pm \\
269.9^{f}\end{array}$ & $\begin{array}{l}968.7^{ \pm} \\
488.2^{\mathrm{g}}\end{array}$ & $\begin{array}{l}972.3 \pm \\
486.6^{h}\end{array}$ & $\begin{array}{l}70.7 \pm \\
21.2^{i}\end{array}$ \\
\hline 42 & $\begin{array}{l}1,137.7 \pm \\
86.7^{a}\end{array}$ & $\begin{array}{l}770.3 \pm \\
389.9^{\mathrm{a}}\end{array}$ & $\begin{array}{l}1,112.3 \pm \\
564.5^{\mathrm{a}}\end{array}$ & $\begin{array}{l}170.0 \pm \\
167.0^{\mathrm{a}}\end{array}$ & $\begin{array}{l}0.0 \pm \\
0.0^{\mathrm{a}}\end{array}$ & $\begin{array}{l}1,212.0 \pm \\
405.6^{a}\end{array}$ & $\begin{array}{l}1,149.3 \\
\pm 29.7^{a}\end{array}$ & $\begin{array}{l}255.3 \pm \\
242.4^{\mathrm{a}}\end{array}$ & $\begin{array}{l}9.0 \pm \\
4.9^{a}\end{array}$ \\
\hline
\end{tabular}

Mean \pm SEM values in the same row with multiple superscripts are statistically significantly different at $P<0.05$ according to Bonferroni Posthoc test.

Mean \pm SEM values in the same row with same and or single superscript are NOT statistically significantly different at $P>0.05$ according to Bonferroni Posthoc test.

Key:

$A, B, C=$ Chicks from the three commercial hatcheries

SEM $=$ Standard error of mean

There was also significant differences at day 21 of age the in mean antibody titres of chicks from $C(2,444.3 \pm 1,110.6)$ administered $0.2 \mathrm{ml}$ of the vaccine and chicks from $B(568.3 \pm 151.2)$ administered $0.5 \mathrm{ml}$ of the vaccine $S C(P<0.01)$, as well as between $C(2,444.3 \pm 1,110.6)$ administered $0.2 \mathrm{ml}$ of the vaccine and chickens from $C(131.7 \pm 69.4)$ administered $0.5 \mathrm{ml}$ of the vaccine $(P<0.001)$ (Table 2). Similarly, there were high significant differences in the mean antibody titres at day 21 of age between chickens from $C 1(2,444.3 \pm 1,110.6)$ and $A 3(881.0 \pm 215.4)(P<0.05)$, hatcheries $C 1(2,444.3 \pm 1,110.6)$ and $B 3$ $(293.7 \pm 168.4)(P<0.001)$ and between hatcheries $C 1(2,444.3 \pm 1,110.6)$ and $C 3(876.0 \pm 539.3)(P<0.05)$ that were vaccinated via SC routes, respectively (Table 2 ).

Results from this study showed that at day 28 of age, there were significant differences between the mean antibody titres between the chicks from $B 1(61.0 \pm 38.4)$ and $A 2(1,639.3 \pm 1,451.8)(P<0.05), B 1(61.0 \pm 38.4)$ and $C 2(1,653.7 \pm 181.3)(P<$ 0.05), A2 (1,639.3 \pm 1451.8$)$ and $B 2(14.0 \pm 1.0)(P<0.05), A 2(1,639.3 \pm 1,451.8)$ and $A 3(182.7 \pm 115.7)(P<0.05), A 2(1,639.3$ $\pm 1,451.8)$ and $B 3(171.3 \pm 171.3)(P<0.05), B 2(14.0 \pm 1.0)$ and $C 2(1,653.7 \pm 181.3)(P<0.05), C 2(1,653.7 \pm 181.3)$ and $A 3$ $(182.7 \pm 115.7)(P<0.05)$ and between chicks from hatcheries $C 2(1,653.7 \pm 181.3)$ and $B 3(171.3 \pm 171.3)(P<0.05)$ that were vaccinated SC (Table 2). At 35 days of age, results showed significant differences in the mean antibody titres between the chicks from $C 1(46.7 \pm 13.5)$ and B2 $(1,500.0 \pm 60.1)(P<0.05)$, as well as between chicks from B2 $(1,500.0 \pm 60.1)$ and C3 (70.7 $\pm 21.2)(\mathrm{P}<0.05)$ vaccinated SC (Table 2$)$

\subsection{Effects of $0.2 \mathrm{ml}$ dose-regime of Avian Influenza H5 Inactivated Vaccine Administered via the Intramuscular and Subcutaneous Routes}




\section{respectively on the Humoral Immune Responses of ISA brown Chickens from different commercial Hatcheries}

Results from this experiment showed that there were no significant differences $(P>0.05)$ in the mean antibody titres at days 14 , 35 and 42 of age between the IM and SC routes of vaccine administration in all the chicks from the three hatcheries that were administered $0.2 \mathrm{ml}$ of the vaccine (Table 3). However, at day 21 of age, findings showed a highly significant difference $(P<$ $0.001)$ in the mean antibody titres in the chicks from hatcheries $A(57.7 \pm 49.9)$ and $C(2,205.0 \pm 409.1)$ administered $0.2 \mathrm{ml}$ of the vaccine IM (Table 3).

At day 21 of age, the difference in the mean antibody titres in the chickens from A ( $57.7 \pm 49.9)$ administered $0.2 \mathrm{ml}$ of the vaccine IM were highly significantly different $(P<0.001)$ compared to the antibody titres of chickens from $C(2,444.3 \pm 1110.6)$ administered $0.2 \mathrm{ml}$ of the vaccine SC. There was also significant differences at day 21 of age in the mean antibody titres of chicks from hatcheries $C$ (SC) $(2,444.3 \pm 1,110.6)$ and $A(I M)(57.7 \pm 49.9)(P<0.001), C$ (IM) $(2,205.0 \pm 409.1)$ and $A$ (SC) (53.3 $\pm 36.0)(P<0.001), A(S C)(53.3 \pm 36.0)$ and $C$ (SC) $(2,444.3 \pm 1,110.6)(P<0.001), B(I M)(260.7 \pm 124.8)$ and $C$ (IM) $(2,205.0 \pm$ 409.1) $(\mathrm{P}<0.001), B(\mathrm{IM})(260.7 \pm 124.8)$ and $C$ (SC) $(2,444.3 \pm 1,110.6)(P<0.001), B(S C)(646.3 \pm 237.9)$ and $C$ (IM) $(2,205.0$ \pm 409.1) $(P<0.01)$, as well as between $B(S C)(646.3 \pm 237.9)$ and $C(S C)(2,444.3 \pm 1,110.6)(P<0.01)$, respectively (Table 3$)$.

Table 3. Effects of $0.2 \mathrm{ml}$ of avian influenza $\mathrm{H} 5$ inactivated vaccine administered at 14 and 28 days of age via either intramuscular or subcutaneous

routes respectively on the humoral immune responses of ISA brown chickens from three different commercial hatcheries in Nigeria

\begin{tabular}{|c|c|c|c|c|c|c|}
\hline & \multicolumn{6}{|c|}{ Source of Chicks } \\
\hline & \multicolumn{2}{|l|}{ Hatchery A } & \multicolumn{2}{|l|}{ Hatchery B } & \multicolumn{2}{|l|}{ Hatchery C } \\
\hline & Intramuscular & Subcutaneous & Intramuscular & Subcutaneous & Intramuscular & Subcutaneous \\
\hline $\begin{array}{l}\text { Age } \\
\text { (days) }\end{array}$ & \multicolumn{2}{|c|}{ Antibody titre (mean \pm SEM) } & \multicolumn{2}{|c|}{ Antibody titre (mean \pm SEM) } & \multicolumn{2}{|c|}{ Antibody titre (mean \pm SEM) } \\
\hline 14 & $293.7 \pm 53.9^{a}$ & $293.7 \pm 53.9^{a}$ & $182.7 \pm 129.1^{a}$ & $182.7 \pm 129.1^{\mathrm{a}}$ & $354.0 \pm 354.0^{a}$ & $354.0 \pm 354.0^{\mathrm{a}}$ \\
\hline 21 & $57.7 \pm 49.9^{\text {aef }}$ & $53.3 \pm 36.0^{\text {bef }}$ & $\begin{array}{l}260.7 \pm \\
124.8^{\text {cef }}\end{array}$ & $646.3 \pm 237.9^{d}$ & $\begin{array}{l}2,205.0 \pm \\
409.1^{\mathrm{de}}\end{array}$ & $\begin{array}{l}2,444.3 \pm \\
1110.6^{\mathrm{df}}\end{array}$ \\
\hline 28 & $\begin{array}{l}424.7 \pm \\
321.4^{a}\end{array}$ & $544.3 \pm 478.0^{\mathrm{b}}$ & $0.0 \pm 0.0^{c}$ & $61.3 \pm 38.4^{d}$ & $\begin{array}{l}1,372.3 \pm \\
341.1^{\text {cde }}\end{array}$ & $371.7 \pm 371.7^{f}$ \\
\hline 35 & $\begin{array}{l}968.7 \pm \\
268.2^{\mathrm{a}}\end{array}$ & $\begin{array}{l}1,271.0 \pm \\
163.7^{a}\end{array}$ & $678.3 \pm 376.8^{a}$ & $\begin{array}{l}1,196.0 \pm \\
113.8^{\mathrm{a}}\end{array}$ & $208.3 \pm 101.7^{a}$ & $46.7 \pm 13.5^{a}$ \\
\hline 42 & $\begin{array}{l}288.3^{ \pm} \\
257.1^{a}\end{array}$ & $1,137.7 \pm 86.7^{a}$ & $4.0 \pm 4.0^{a}$ & $770.3 \pm 389.9^{a}$ & $932.3 \pm 550.3^{a}$ & $1,112.3 \pm 564.5^{a}$ \\
\hline
\end{tabular}

Mean \pm SEM values in the same row with multiple superscripts are statistically significantly different at $\mathrm{P}<0.05$ according to Bonferroni Posthoc test.

Mean \pm SEM values in the same row with same and or single superscript are not statistically significantly different at $P>0.05$ according to Bonferroni Posthoc test.

Table 4. Effects of $0.5 \mathrm{ml}$ of avian influenza $\mathrm{H} 5$ inactivated vaccine administered at 14 and 28 days of age via either intramuscular or subcutaneous 
routes respectively on the humoral immune responses of ISA brown chickens from three different commercial hatcheries in Nigeria

\begin{tabular}{|c|c|c|c|c|c|c|}
\hline & \multicolumn{6}{|c|}{ Source of Chicks } \\
\hline & \multicolumn{2}{|l|}{ Hatchery A } & \multicolumn{2}{|l|}{ Hatchery B } & \multicolumn{2}{|l|}{ Hatchery C } \\
\hline & Intramuscular & Subcutaneous & Intramuscular & Subcutaneous & Intramuscular & Subcutaneous \\
\hline $\begin{array}{l}\text { Age } \\
\text { (days) }\end{array}$ & \multicolumn{2}{|c|}{ Antibody titre (mean \pm SEM) } & \multicolumn{2}{|c|}{ Antibody titre (mean \pm SEM) } & \multicolumn{2}{|c|}{ Antibody titre (mean \pm SEM) } \\
\hline 14 & $27.3 \pm 21.6^{a}$ & $27.3 \pm 21.6^{a}$ & $69.3 \pm 16.6^{a}$ & $69.3 \pm 16.6^{a}$ & $82.0 \pm 43.1^{\mathrm{a}}$ & $82.0 \pm 43.1^{\mathrm{a}}$ \\
\hline 21 & $776.7 \pm 420.0^{a}$ & $469.3 \pm 444.1^{\mathrm{bf}}$ & $\begin{array}{l}399.0^{ \pm} \\
160.1^{\mathrm{c}}\end{array}$ & $\begin{array}{l}568.3 \pm \\
151.2^{\mathrm{df}}\end{array}$ & $\begin{array}{l}1,993.0 \pm \\
978.4^{\text {ef }}\end{array}$ & $131.7 \pm 69.4^{f}$ \\
\hline 28 & $59.0 \pm 59.0^{a}$ & $\begin{array}{l}1,639.3 \pm \\
1451.8^{\mathrm{abcd}}\end{array}$ & $84.0 \pm 51.3^{c}$ & $14.0 \pm 1.0^{d}$ & $576.7 \pm 500.7^{e}$ & $\begin{array}{l}1,653.7 \pm \\
181 \cdot 3^{\text {acdf }}\end{array}$ \\
\hline 35 & $\begin{array}{l}1,080.7 \pm \\
224.2^{\mathrm{a}}\end{array}$ & $1169.3 \pm 248.1^{\mathrm{a}}$ & $\begin{array}{l}642.0^{ \pm} \\
341.1^{\mathrm{a}}\end{array}$ & $\begin{array}{l}1,500.0 \pm \\
60.1^{\mathrm{a}}\end{array}$ & $135.0 \pm 84.5^{a}$ & $392.0 \pm 269.9^{a}$ \\
\hline 42 & $\begin{array}{l}1,327.3 \pm \\
199.3^{\mathrm{a}}\end{array}$ & $170.0 \pm 167.0^{b}$ & $\begin{array}{l}775.3 \pm \\
399.0^{c}\end{array}$ & $0.0 \pm 0.0^{d}$ & $\begin{array}{l}1,822.3 \pm \\
176.7^{\mathrm{de}}\end{array}$ & $\begin{array}{l}1,212.0 \pm \\
405.6^{\mathrm{bf}}\end{array}$ \\
\hline
\end{tabular}

Mean \pm SEM values in the same row with multiple superscripts are statistically significantly different at $P<0.05$ according to Bonferroni Posthoc test.

Mean \pm SEM values in the same row with same and or single superscript are not statistically significantly different at $P>0.05$ according to Bonferroni Posthoc test.

Results further showed that at day 28 of age, there were also significant differences in the mean antibody titres between chicks from $B(I M)(0.0 \pm 0.0)$ and $C(I M)(1,372.3 \pm 341.1)(P<0.05)$, as well as between hatcheries $B(S C)(61.3 \pm 38.4)$ and $C$ (IM) $(1,372.3 \pm 341.1)(P<0.05)($ Table 3$)$.

\subsection{Effects of $0.5 \mathrm{ml}$ dose-regime of Avian Influenza H5 Inactivated Vaccine Administered via the Intramuscular and Subcutaneous Routes respectively on the Humoral Immune Responses of ISA brown chicks from different commercial Hatcheries in Nigeria}

There were no significant differences $(P>0.05)$ in the mean antibody titres at days 14 and 35 of age between the IM and SC routes of vaccine administration in all the chicks from the three hatcheries administered $0.5 \mathrm{ml}$ of the vaccine (Table 4). However, at day 21 of age, findings showed a significant difference in the mean antibody titres in chicks from hatcheries $\mathrm{A}$ $(469.3 \pm 444.1)$ and $\mathrm{C}(131.7 \pm 69.4)$ that were administered $0.5 \mathrm{ml}$ of the vaccine $\mathrm{SC}(\mathrm{P}<0.05), \mathrm{B}(\mathrm{IM})(399.0 \pm 160.1)$ and $\mathrm{C}$ (IM) $(1,993.0 \pm 978.4)(P<0.05)$, as well as between C (IM) $(1,993.0 \pm 978.4)$ and C (SC) $(131.7 \pm 69.4)(P<0.01)(T a b l e 4)$. Results also showed that at day 28 of age, the difference in the mean antibody titres in the chicks from A administered $0.5 \mathrm{ml}$ of the vaccine IM $(59.0 \pm 59.0)$ was significantly different when compared to the antibody titres of chicks from the same $A$ administered the same dose of the H5 vaccine SC $(1,639.3 \pm 1,451.8)(P<0.05)$ (Table 4). There were also significant differences at day 28 of age in mean antibody titres of chicks from hatcheries A (IM) (59.0 \pm 59.0$)$ and C (SC) $(1,653.7 \pm 181.3)$ $(P<0.05), A(S C)(1,639.3 \pm 1451.8)$ and $B(I M)(84.0 \pm 51.3)(P<0.05), A(S C)(1,639.3 \pm 1,451.8)$ and $B(S C)(14.0 \pm 1.0)(P<$ 0.05), $B(I M)(84.0 \pm 51.3)$ and C (SC) $(1,653.7 \pm 181.3)(P<0.05)$, as well as between B (SC) $(14.0 \pm 1.0)$ and $C$ (SC) $(1,653.7 \pm$ 181.3) $(\mathrm{P}<0.05)$ administered $0.5 \mathrm{ml}$ of the vaccine (Table 4$)$. Results from this study showed that at 42 days of age, there were also significant differences in the mean antibody titres of chicks from hatcheries $A(S C)(170.0 \pm 167.0)$ and $C$ (SC) $(1,212.0 \pm$ 405.6) $(P<0.05)$, as well as between $B(S C)(0.0 \pm 0.0)$ and $C(I M)(1,822.3 \pm 176.7)(P<0.01)($ Table 4$)$.

\subsection{Effects of $0.7 \mathrm{ml}$ dose-regime of Avian Influenza H5 Inactivated Vaccine Administered}




\section{via the Intramuscular and Subcutaneous Routes respectively on the Humoral Immune}

\section{Responses of ISA brown chickens from different commercial Hatcheries in Nigeria}

There were no significant differences $(P>0.05)$ in the mean antibody titres at days 14,28 and 35 of age between the IM and SC routes of vaccine administration in all the chicks from the three commercial hatcheries administered $0.7 \mathrm{ml}$ of the $\mathrm{H} 5$ vaccine (Table 5). However, at day 21 of age, there were high significant differences in the mean antibody titres in the chicks from hatcheries $A(212.3 \pm 209.8)$ and $C(1,834.3 \pm 638.9)$ administered $0.7 \mathrm{ml}$ of the vaccine IM $(P<0.001), B(I M)(221.7 \pm 51.6)$ and C (IM) $(1,834.3 \pm 638.9)(P<0.001)$, as well as between B (SC) $(293.7 \pm 168.4)$ and C (IM) $(1,834.3 \pm 638.9)(P<0.001)$ (Table 5). Furthermore, results showed that at day 42 of age, there were significant differences in the mean antibody titres of chickens from hatcheries $A(I M)(66.7 \pm 20.4)$ and $A(S C)(1,149.3 \pm 29.7)(P<0.05), A(S C)(1,149.3 \pm 29.7)$ and $B(I M)(2.7 \pm$ 2.7) $(P<0.05)$, as well as between $A(S C)(1,149.3 \pm 29.7)$ and $C(S C)(9.0 \pm 4.9)(P<0.01)$ (Table 5).

Table 5. Effects of $0.7 \mathrm{ml}$ of avian influenza $\mathrm{H} 5$ inactivated vaccine administered at 14 and 28 days of age via either intramuscular or subcutaneous

routes respectively on the humoral immune responses of ISA brown chickens from three different commercial hatcheries in Nigeria

\begin{tabular}{|c|c|c|c|c|c|c|}
\hline & \multicolumn{6}{|c|}{ Source of Chicks } \\
\hline & \multicolumn{2}{|l|}{ Hatchery A } & \multicolumn{2}{|l|}{ Hatchery B } & \multicolumn{2}{|l|}{ Hatchery C } \\
\hline & Intramuscular & Subcutaneous & Intramuscular & Subcutaneous & Intramuscular & Subcutaneous \\
\hline $\begin{array}{l}\text { Age } \\
\text { (days) }\end{array}$ & \multicolumn{2}{|c|}{ Antibody titre (mean \pm SEM) } & \multicolumn{2}{|c|}{ Antibody titre (mean \pm SEM) } & \multicolumn{2}{|c|}{ Antibody titre (mean \pm SEM) } \\
\hline 14 & $89.0 \pm 65.2^{a}$ & $89.0 \pm 65.2^{a}$ & $88.7 \pm 88.7^{a}$ & $88.7 \pm 88.7^{a}$ & $203.0 \pm 191.1^{a}$ & $\begin{array}{l}203.0 \pm \\
191.1^{a}\end{array}$ \\
\hline 21 & $\begin{array}{l}212.3 \pm \\
209.8^{a}\end{array}$ & $881.0 \pm 215.4^{b}$ & $221.7 \pm 51.6^{c}$ & $\begin{array}{l}293.7 \pm \\
168.4^{d}\end{array}$ & $\begin{array}{l}1,834.3 \pm \\
638.9^{\text {acde }}\end{array}$ & $876.0 \pm 539.3^{f}$ \\
\hline 28 & $47.0 \pm 44.0^{\mathrm{a}}$ & $182.7 \pm 115.7^{a}$ & $0.0 \pm 0.0^{a}$ & $\begin{array}{l}171.3 \pm \\
171.3^{\mathrm{a}}\end{array}$ & $703.0 \pm 352.0^{a}$ & $\begin{array}{l}321.7 \pm \\
218.6^{a}\end{array}$ \\
\hline 35 & $\begin{array}{l}566.3 \pm \\
351.8^{\mathrm{a}}\end{array}$ & $968.7 \pm 488.2^{a}$ & $\begin{array}{l}970.0 \pm \\
486.2^{\mathrm{a}}\end{array}$ & $\begin{array}{l}972.3 \pm \\
486.6^{a}\end{array}$ & $214.0 \pm 74.3^{a}$ & $70.7 \pm 21.2^{a}$ \\
\hline 42 & $66.7 \pm 20.4^{a}$ & $\begin{array}{l}1,149.3 \pm \\
29.7^{\text {abce }}\end{array}$ & $2.7 \pm 2.7^{c}$ & $\begin{array}{l}255.3 \pm \\
242.4^{d}\end{array}$ & $687.0 \pm 393.5^{e}$ & $9.0 \pm 4.9^{f}$ \\
\hline
\end{tabular}

Mean \pm SEM values in the same row with multiple superscripts are statistically significantly different at $\mathrm{P}<0.05$ according to Bonferroni Posthoc test.

Mean \pm SEM values in the same row with same and or single superscript are not statistically significantly different at $P>0.05$ according to Bonferroni Posthoc test.

\section{Discussion}

The route and or dose of administration of biologics are fundamental in the pathodynamics and or recovery rate and pattern of any disease process in an individual (Ezan, 2013). Most inactivated vaccines are usually administered either intramuscularly or 
subcutaneously (Nataša, 2014); however, very few studies have directly compared the immunogenicity and reactogenicity of the same vaccine administered via these routes. The findings from the present study showed significant differences at day 14 of age for both the intramuscular and subcutaneous routes across all treatment groups. This could be due to the presence of MDAs in the groups as samples were collected prior to vaccination with the inactivated Al H5 vaccine. The findings from this study also indicated that after two doses of the Al H5 vaccine inactivated vaccine (primary and booster), there were delayed seroconversions and varied immunogenicity (expressed as antibody levels) in all the chicks when administered via the intramuscular route, irrespective of dose. Some chicks showed high ELISA titre levels, whereas others showed low ELISA titre levels or were even seronegative. Specifically, ELISA titres post-vaccination of individual chicks from hatchery C differed significantly from those of chicks from hatcheries A and B. These variations in seroconversion could be attributed to the high levels of maternally derived antibodies in all the chicks sampled, especially after the primary vaccine dose. Likewise, these differences may have been due to the impacts of environmental factors such as temperature and lighting (Tung et al., 2013) on individual chick's immune apparatus in response to the immunogen. These results are consistent with the findings of Tarigan et al. (2018) who reported that the outcomes of field Al H5N1 vaccination were highly variable and farm-related. Our speculations are also in tandem with Kapcznski et al. (2016) who stated that interference by maternally derived antibodies can render inactivated vaccines impotent.

Although several studies have shown that more than one vaccination dose is required to induce protective immunity and prevent H5N1 HPAl transmission in ducks and other poultry in field conditions (Swayne, 2009; Lecu et al., 2009; van der Goot et al., 2007; Pantin-Jackwood and Suarez, 2013), the present study showed that although there was delayed seroconversion to the Al H5 vaccine in all the chicks, the mean ELISA antibody titres varied significantly based on the dose of antigen injected intramuscularly. These variations could be due to the varied level of anamnestic (memory) immune responses in all the chicks as well as the immunogenic potential of the vaccine virus used in the vaccine. Variations in immunogenicity observed in this study after intramuscular injection of the antigen at different dose levels could be due to the quality of the $\mathrm{H} 5$ vaccine used as well as the chicks' antigen processing capabilities. The decreased variability in antibody responses even after booster vaccination that was observed in this study has important implications in terms of the effectiveness of avian influenza vaccination program as immune escape and antigenic drift, as a result of the selective pressure induced by immunization, may be one of the critical reasons behind vaccine failure as previously reported (Smith et al., 2006; Pu et al., 2015). These results suggest that vaccination may actually play a role in driving the evolution of AIVs (Smith et al., 2006; Pu et al., 2015), as the vaccinated animals may then act as silent carriers for AIVs, spreading the virus to naive animals through poultry transports or Live Bird Markets (Chen et al., 2009; Guan and Smith, 2013; Bi et al., 2015; Pu et al., 2015).

Although the chicks from $\mathrm{C}$ had higher antibody ELISA titres than chicks from hatcheries $\mathrm{A}$ and $\mathrm{B}$ when $0.2 \mathrm{ml}$ and $0.5 \mathrm{ml}$ of the Al H5 inactivated vaccine were administered either via the intramuscular or subcutaneous routes respectively (which were more significant at 21 and 28 and 21, 28 and 42 days of age for the $0.2 \mathrm{ml}$ and $0.5 \mathrm{ml}$ doses respectively), findings revealed that the antigen was more immunogenic when administered subcutaneously in comparison to the intramuscular route for chicks from the three commercial hatcheries studied. Likewise, at 21 and 42 days of age, the chicks administered $0.7 \mathrm{ml}$ of the antigen from the different hatcheries via the both routes showed that although there were varied antibody titres between the chicks, the antigen was more immunogenic in the chicks from $C$ than from hatcheries $A$ and $B$ when the antigen was administered subcutaneously. These differences in the immunogenicity of the $\mathrm{H} 5$ vaccine injected via the intramuscular and subcutaneous routes could be due to "depot effects" emanating from subcutaneous fat issues in the animals which aid in the slow but prolonged release of vaccines. This possibility is in agreement with the findings from previous studies (Didierlaurent et al., 2014; Malissen et al., 2014). Also, the observed enhanced immunogenicity via subcutaneous route compared to the intramuscular route in the present study could be attributable to the marked differences in the cellular composition of muscle and dermal tissues that may affect these vaccination outcomes. For instance, the subcutaneous fat beds contain few immune cells; however, they are adjacent to the skin dermal layers, which contain higher numbers of lymphocytes, macrophages, and specialized dermal dendritic cells (DCs) that drain into the local lymph node, whereas muscle tissue contains few immune cells and very low DC numbers (Didierlaurent et al., 2014; Malissen et al., 2014). These arguments are in tandem with previous studies in murine where it was noted that the DC populations in lymph nodes draining the intramuscular and subcutaneous sites of injections were different, which may lead to altered antigen-specific immune responses (Guilliams et al., 2010). However, 
little is known regarding the trafficking of cells within the lymphatic vessels that connect the muscle injection site with the local lymph node and whether this may contribute to altered immune responses observed between the routes of administration. Although previous works have shown that subcutaneous injections of adjuvanted inactivated vaccines are associated with increased rates of site reactions compared to the intramuscular vaccinations (Cook, 2008; Diez-Domingo et al., 2015), the present study detected very minimal reaction at the site of subcutaneous injection of the antigen (nape of the neck).

Primary and booster vaccinations are immunogenic and could induce antibody responses in ducks at levels that meet the targets of the national mass vaccination program. Results from a recent study in ducks support the notion that compared with the single-dose immunization regimen, the two-dose immunization regimen more intensely induced protective antibody production and, thus, provides better humoral immunity against the HPAl virus (Huynh et al., 2019). Furthermore, the single-dose vaccination regimen has been shown to be suitable for short-lived meat ducks, whereas two-dose vaccination regimen is suitable for long-lived ducks, as for layers or breeders, to increase their protective humoral immunity and strengthen flock immunity (Huynh et al., 2019). However, the findings of the present study showed that in spite of booster vaccination, there were significant intra-and inter-route variations in immunogenicity of the $\mathrm{H} 5$ vaccine at certain ages of the chicks, even at same and or different antigen dose levels. This variability could be due to the possible differences in immune-competences of chicks within the same hatchery population as well as differences in the lymphatic drainages between the intramuscular and subcutaneous sites of antigen administration. The findings from the current study also showed that the immunity in the different groups of chicks varied considerable in response to the same and or different dose of antigen administered. These findings further reiterate the possible variable outcomes in field vaccination with $\mathrm{H} 5 \mathrm{Al}$ inactivated vaccines in a population.

In conclusion, the present study has shown that the immunity in a population varied considerable in the face of the same and or different dose of $\mathrm{H} 5$ vaccine administered, reiterating the variable outcomes in field vaccination with $\mathrm{H} 5 \mathrm{Al}$ inactivated vaccines in a population. Also, the immune response of the chicks to the Al H5 vaccine via different routes in this study was variable at 21 and 35 days of age for the IM and SC routes, respectively. Therefore, further studies should be conducted to characterize the $\mathrm{T}$ - and B-lymphocytes in chickens post Al H5 vaccines administration, and studies evaluating sequence homologies between imported Al H5 vaccines and the circulating AIV strains in Nigeria be conducted.

\section{Declarations}

Funding: This research was funded by the Tertiary Education Trust Fund (tetFund) of the Federal Ministry of Education, Nigeria, under the Institutional Based Research grant for Ahmadu Bello University, Zaria (Grant No.: DAPM/TETFUND/01/12).

Conflicts of interest/Competing interests: The Authors declare that there is no conflict of interest in the outcomes of this research.

Ethics approval: Ethical approval for this study was obtained from the Animal Care and Use for Research Committee of Ahmadu Bello University, Zaria (approval number: ABUCAUC/2019/23). The chickens and methods for the experiments were handled and conducted in accordance with the International Standards for the Care and Use of Laboratory Animals for Research Purposes.

\section{Consent to participate: Not applicable}

\section{Consent for publication: Not applicable}

\section{Availability of data and material: Not applicable}

\section{Code availability: Not applicable}

Authors' contributions: Conceptualization: Woziri OA, Abdu PA, Meseko CA and Fasina FO; Methodology: Woziri OA, Abdu PA and Adamu J; Formal analysis and investigation: Woziri OA, Abdu PA, Nasir FI and Abdulkarim K; Writing - original draft preparation: Woziri OA, Abdu PA and Meseko, CA; Writing - review and editing: Woziri OA, Abdu PA, Meseko, CA and Fasina FO; Funding acquisition: Woziri OA; Resources: Woziri OA, Abdu PA, Nasir FI and Abdulkarim K; Supervision: Abdu PA. 


\section{Acknowledgements}

The authors graciously thank Zoetis Int, USA for the kind donation of the ProFlok ${ }^{\circledR}$ ELISA kits for this research. They also wish to thank Mr. Edima Obaja, David Leo and Yahuza Maitalla of the Faculty of Veterinary Medicine, Ahmadu Bello University, Nigeria, for their technical assistance during the course of this research.

\section{References}

Abdallah, F. and Hassanin, O. 2015. Positive regulation of humoral and innate immune responses induced by inactivated Avian Influenza Virus vaccine in broiler chickens. Veterinary Research Communications, 1-6.

Bi, Y., Mei, K., Shi, W., Liu, D., Yu, X., Gao, Z., Zhao, L., Gao, G. F., Chen, J. and Chen, Q. 2015. Two novel reassortants of avian influenza A (H5N6) virus in China. Journal of General Virology, 96, 975--981.

Brown, I. H. 2010.Summary of avian influenza Activity in Europe, Asia, and Africa: 2006-2009. Avian Diseases, 54(1), 187-193.

Chen, H. 2009. Avian influenza vaccination: the experience in China. Review of Science and Technology, 28, 267-274.

Chen, J., Fang, F., Yang, Z., Liu, X., Zhang, H., Zhang, Z., Zhang, X. and Chen, Z. 2009. Characterization of highly pathogenic H5N1 avian influenza viruses isolated from poultry markets in central China. Virus Research, 146, 19-28.

Cook, I. F. 2008. Evidence based route of administration of vaccines. Human Vaccines, 4, 67-73.

Didierlaurent, A. M., Collignon, C., Bourguignon, P., Wouters, S., Fierens, K., Fochesato, M., Dendouga, N., Langlet, C., Malissen, B. and Lambrecht, B. N. 2014. Enhancement of adaptive immunity by the human vaccine adjuvant AS01 depends on activated dendritic cells. Journal of Immunology, 193, 1920-1930.

Diez-Domingo, J., Weinke, T., Garcia de Lomas, J., Meyer, C. U., Bertrand, I., Eymin, C., Thomas, S. and Sadorge, C. 2015. Comparison of intramuscular and subcutaneous administration of a herpes zoster live-attenuated vaccine in adults aged $\$ 50$ years: a randomised non-inferiority clinical trial. Vaccine, 33, 789--795.

Ezan E. 2013. Pharmacokinetic studies of protein drugs: past, present and future. Advances in Drug Delivery Review, 65(8), 1065-1073.

Germundsson, A., Madslien, K. I., Hjortaas, M. J., Handeland, K. and Jonassen, C. M. 2010. Prevalence and subtypes of influenza A viruses in wild waterfowl in Norway 2006-2007. Acta Veterinaria Scandinavica, 52, 28.

Guan, Y. and Smith, G. J. 2013. The emergence and diversification of panzootic H5N1 influenza viruses. Virus Research, 178, 35$-43$.

Guilliams, M., Henri, S., Tamoutounour, S., Ardouin, L., Schwartz-Cornil, I., Dalod, M. and Malissen, B. 2010. From skin dendritic cells to a simplified classification of human and mouse dendritic cell subsets. European Journal of Immunology, 40, $2089-094$.

Huynh, H. T. T., Truong, L. T., Meeyam, T., Le, H. T. and Punyapornwithaya, V. 2019. Individual and flock immunity responses of naïve ducks on smallholder farms after vaccination with H5N1 avian influenza vaccine: a study in a province of the Mekong Delta, Vietnam. PeerJ, 1, 14.

Jang, Y. H. and Seong, B. L. 2019. The quest for a truly universal influenza vaccine. Frontiers in Cellular and Infection Microbiology, 9(344), 1-24.

Juno, J., Fowke, K. R. and Keynan, Y. 2012. Immunogenetic factors associated with severe respiratory illness caused by zoonotic H1N1 and H5N1 influenza viruses. Clinical and Developmental Immunology, 2012, 797180. 
Kang, H. M., Jeong, O. M., Kim, M. C., Kwon, J. S., Paek, M. R., Choi, J. G., Lee, E. K., Kim, Y. J., Kwon, J. H. and Lee, Y. J. 2010. Surveillance of avian influenza virus in wild bird fecal samples from South Korea, 2003-2008. Journal of Wildlife Diseases, 46(3), 878-888.

Kapczynski, D. R., Liljebjelke, K., Kulkarni, G., Hunt, H., Jiang, H. J. and Petkov, D. 2011. Cross reactive cellular immune responses in chickens previously exposed to low pathogenic avian influenza. BMC Proceeding, , 5, S13.

Kapczynski, D. R., Pantin-Jackwood, M., Guzman, S. G., Ricardez, Y., Spackman, E. and Bertran, K. 2013. Characterization of the 2012 highly pathogenic avian influenza H7N3 virus isolated from poultry in an outbreak in Mexico: pathobiology and vaccine protection. Journal of Virology, 87(16), 9086-9096.

Kapczynski, D. R., Tumpey, T. M., Hidajat, R., Zsak, A., Chrzastek, K. and Tretyakova, I. 2016. Vaccination with virus-like particles containing H5 antigens from three H5N1 clades protects chickens from H5N1 and H5N8 influenza viruses. Vaccine, 34(13), 1575-1581.

Lecu, A., De Langhe, C., Petit, T., Bernard, F. and Swam, H. 2009. Serologic response and safety to vaccination against avian influenza using inactivated H5N2 vaccine in zoo birds. Journal of Zoo and Wildlife Medicine, 40(4), 731-743.

Malissen, B., Tamoutounour, S. and Henri, S. 2014. The origins and functions of dendritic cells and macrophages in the skin. Nature Reviews Immunology, 14, 417--428.

Marchenko, V. Y., Alekseev, A. Y., Sharshov, K. A., Petrov, V. N., Silko, N. Y., Susloparov, I. M., Tserennorov, D., Otgonbaatar, D., Savchenko, I. A. and Shestopalov, A. M. 2012. Ecology of influenza virus in wild bird populations in Central Asia. Avian Diseases, 56(1), 234-237.

Nataša Š. B. 2014. Biologics: the role of delivery systems in improved therapy. Biologics: Targets and Therapy, 8, 107-114.

Nolan, T. M., Richmond, P. C., Skeljo, M. V., Pearce, G., Hartel, G. and Formica, N. T. 2008. Phase I and II randomised trials of the safety and immunogenicity of a prototype adjuvanted inactivated split-virus influenza A (H5N1) vaccine in healthy adults. Vaccine, 26, 4160-4167.

Oladokun, A. T., Meseko, C. A., Ighodalo E., John, B. and Ekong, P. 2012. Effect of intervention on the control of Highly Pathogenic Avian Influenza in Nigeria. Pan African Medical Journal, 1-8.

Pantin-Jackwood, M. J. and Suarez, D. L. 2013. Vaccination of domestic ducks against H5N1 HPAl: a review. Virus Research, 178(1), 21-34.

Pu, J., Wang, S., Yin, Y., Zhang, G., Carter, R. A., Wang, J., Xu, G., Sun, H., Wang, M., Wen, C., Wei, Y., Wang, D., Zhu, B., Lemmon, G., Jiao, Y., Duan, S., Wang, Q., Du, Q., Sun, M., Bao, J., Sun, Y., Zhao, J., Zhang, H., Wu, G., Liu, J. and Webster, R. G. 2015. Evolution of the H9N2 influenza genotype that facilitated the genesis of the novel H7N9 virus. Proceedings of National Academy of Science, $112,548-553$.

Sautto, G. A., Kirchenbaum, G. A. and Ross, T. M. 2018. Towards a universal influenza vaccine: different approaches for one goal. Virology Journal, 15(17), 1-12.

Singh, S. M., Alkie, T. N., Hodgins, D. C., Nagy, É., Shojadoost, B. and Sharif, S. 2015. Systemic immune responses to an inactivated, whole H9N2 avian influenza virus vaccine using class B CpG oligonucleotides in chickens. Vaccine, 33, $3947-3952$.

Smith, G. J., Fan, X. H., Wang, J., Li, K. S., Qin, K., Zhang, J. X, Vijaykrishna, D., Cheung, C. L., Huang, K., Rayner, J. M., Peiris, J. S., Chen, H., Webster, R. G. and Guan, Y. 2006. Emergence and predominance of an H5N1 influenza variant in China. Proceedings of National Academy of Science,103, 16936-16941.

Swayne, D. E. and Kapczynski, D. R. 2009. Vaccines, vaccination, and immunology for avian influenza viruses in poultry. In Avian Influenza, Blackwell Publishing Ltd, pp., 407-451.

Page $14 / 15$ 
Swayne, D. E. and Kapczynski, D. 2008. Strategies and challenges for eliciting immu-nity against avian influenza virus in birds. Immunological Reviews, 225, 314-331.

Swayne, D. E. 2008. Avian influenza. In: Foreign Animal Diseases, Boca Raton, FL: United States Animal Health Association, pp. 137-146.

Swayne, D. E. 2015. Overview of avian influenza. In: Aiello, S. E., Moses, M. A, editors. The Merck Veterinary Manual (online). Whitehouse Station, NJ, Merck and Co.

Swayne, D.E., Spackman, E. \& Pantin-Jackwood, M. 2014. Success Factors for Avian Influenza Vaccine Use in Poultry and Potential Impact at the Wild Bird-Agricultural Interface. EcoHealth, 11, 94-108.

Tarigan, S., Wibowo, M. H., Indriani, R., Sumarningsih, S., Artanto, S., Idris, S., Durr, P. A., Asmara, W., Ebrahimie, E., Stevenson, M. A. and Ignjatovic, J. 2018. Field effectiveness of highly pathogenic avian influenza H5N1 vaccination in commercial layers in Indonesia. PLoS ONE, 13(1), e0190947.

Tonnessen, R., Kristoffersen, A. B., Jonassen, C. M., Hjortaas, M. J., Hansen, E. F., Rimstad, E. and Hauge, A. G. 2013. Molecular and epidemiological characterization of avian influenza viruses from gulls and dabbling ducks in Norway. Virology Journal, 10, 112.

Tung, D. H., Van Quyen, D., Nguyen, T., Xuan, H. T., Nam, T. N. and Duy, K. D. 2013. Molecular characterization of a H5N1 highly pathogenic avian influenza virus clade 2.3.2.1b circulating in Vietnam in 2011. Veterinary Microbiology, 165(3-4), 341-348.

van den Berg, T., Lambrecht, B., Marché, S., Steensels, M., Van Borm, S. and Bublot, M. 2008. Influenza vaccines and vaccination strategies in birds. Comparative Immunology, Microbiology and Infectious Diseases, 31, 121-165.

Van der Goot, J. A., Van Boven, M., De Jong, M. C. and Koch, G. 2007. Effect of vaccination on transmission of HPAI H5N1: the effect of a single vaccination dose on transmission of highly pathogenic avian influenza H5N1 in Peking ducks. Avian Diseases, $51(1), 323-324$.

Wille, M., Huang, Y., Robertson, G. J., Ryan, P., Wilhelm, S. I. and Fifield, D. 2014. Evaluation of seabirds in Newfoundland and Labrador, Canada, as hosts of influenza A viruses. Journal of Wildlife Diseases, 50(1), 98-103. 